\title{
Landscape Pattern Response to Changes in the Pattern Generation Rules: Land-use Legacies in Forestry
}

David O. Wallin

Western Washington University, david.wallin@wwu.edu

Frederick J. (Frederick John) Swanson

Pacific Northwest Research Station (Corvallis, Or.)

Barbara J. Marks

Oregon State University

Follow this and additional works at: https://cedar.wwu.edu/esci_facpubs

Part of the Natural Resources Management and Policy Commons

\section{Recommended Citation}

Wallin, David O.; Swanson, Frederick J. (Frederick John); and Marks, Barbara J., "Landscape Pattern Response to Changes in the Pattern Generation Rules: Land-use Legacies in Forestry" (1994). Environmental Sciences Faculty and Staff Publications. 21.

https://cedar.wwu.edu/esci_facpubs/21 


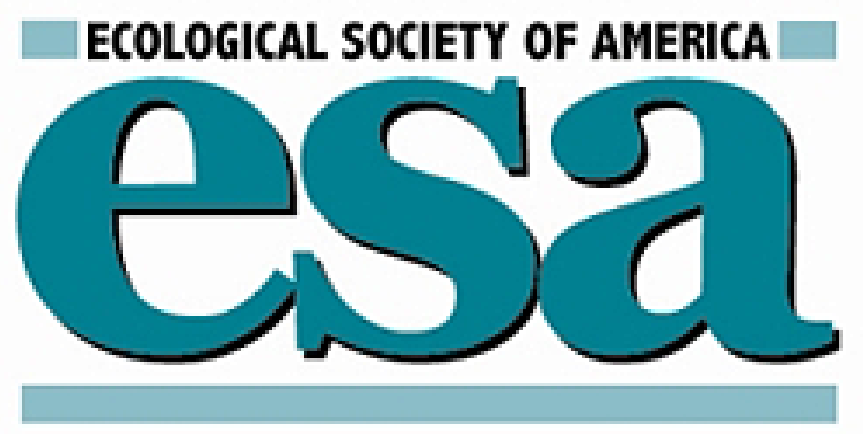

Landscape Pattern Response to Changes in Pattern Generation Rules: Land-Use Legacies in Forestry

Author(s): David O. Wallin, Frederick J. Swanson and Barbara Marks

Source: Ecological Applications, Vol. 4, No. 3 (Aug., 1994), pp. 569-580

Published by: Ecological Society of America

Stable URL: http://www.jstor.org/stable/1941958

Accessed: 01/12/2014 14:51

Your use of the JSTOR archive indicates your acceptance of the Terms \& Conditions of Use, available at http://www.jstor.org/page/info/about/policies/terms.jsp

JSTOR is a not-for-profit service that helps scholars, researchers, and students discover, use, and build upon a wide range of content in a trusted digital archive. We use information technology and tools to increase productivity and facilitate new forms of scholarship. For more information about JSTOR, please contact support@jstor.org. 


\title{
LANDSCAPE PATTERN RESPONSE TO CHANGES IN PATTERN GENERATION RULES: LAND-USE LEGACIES IN FORESTRY ${ }^{1}$
}

\author{
DAVID O. WALLIN \\ Department of Forest Science, Oregon State University, Corvallis, Oregon 97331 USA
}

FREDERICK J. Swanson

USDA Forest Service, Pacific Northwest Research Station, 3200 Jefferson Way, Corvallis, Oregon 97331 USA

BARBARA MARKS

Department of Forest Science, Oregon State University, Corvallis, Oregon 97331 USA

\begin{abstract}
The Pacific Northwest of the United States is currently embroiled in an acrimonious debate over the management of federal forest lands. Constructive resolution of this debate will require better information on a broad range of forest management issues. This study focuses on one such issue: the development of landscape pattern in response to alternative forest cutting plans and the degree to which established landscape patterns can be changed. Dispersed cutting has been conducted on federal lands in the western United States for $>40 \mathrm{yr}$, but alternative cutting plans are now being considered. To assess the effects of different disturbance processes on the development of landscape pattern, we compare dispersed- and aggregated-cutting plans using a simple, rule-based simulation model that incorporates realistic regulatory and logistic constraints. Our results indicate that, once established, the landscape pattern created by dispersed disturbances is difficult to erase without a substantial reduction in the disturbance rate or a reduction in the minimum stand age eligible for disturbance. Change in landscape pattern can lag substantially behind change in the rules governing pattern generation.
\end{abstract}

Key words: disturbance; forest fragmentation; forest management; landscape pattern dynamics; land use; pattern and process; simulation model.

\section{INTRODUCTION}

There is a rich tradition in ecology of studying the relationship between pattern and process (Watt 1947, Bormann and Likens 1979, McIntosh 1985, Cale et al. 1989, Turner 1989). Many studies have examined the role of natural disturbance processes in the creation of spatial patterns (Steele 1978, White 1979, Paine and Levin 1981, Mooney and Godron 1983, Picket and White 1985). These studies have usually been conducted by first describing spatial patterns and then inferring the characteristics of the processes that produced them. It has rarely been possible to directly manipulate the disturbance process to examine the effect on spatial pattern. A few studies have begun to question whether spatial patterns are always a reliable indicator of the ecological processes that created them (Cale et al. 1989).

Here we use a simulation model that enables us to manipulate the characteristics of a disturbance process and examine the resulting landscape patterns and rates of pattern change. The model simulates the forest cutting process on federal lands in the Pacific Northwest (PNW) of the United States. The character of the forest cutting process, and many other disturbance processes, can be defined by a set of rules. In the case of natural

${ }^{1}$ Manuscript received 11 January 1993; revised 30 August 1993; accepted 31 August 1993. disturbance processes, these rules may have a substantial stochastic component. Although the forest cutting process is much more deterministic than most natural disturbance processes, the simple model presented here provides a number of important general lessons regarding landscape pattern response to changes in the character of the disturbance process.

Over the past several decades, public forests in the PNW and elsewhere have been cut using a dispersed ("staggered setting") cutting process that widely distributes 10-20 ha cutting units across the landscape. The rules governing this cutting process were originally conceived to promote forest regeneration by seed rain from adjacent stands, to rapidly develop a road network that could be used for fire suppression and other management activities, to create edge and early-seral habitat favored by many game animals, to disperse the hydrologic and sediment production effects of cutting, and to minimize the visual effects of clear-cut areas (Smith 1985). At present, many of these original objectives have been met or superseded and new objectives have emerged. Reliance on natural regeneration has been abandoned in favor of manual planting of seedlings. The primary transportation network is largely complete. Although this network does facilitate a range of management activities, including fire suppression efforts, most ignitions are anthropogenic and closely associated with the road network (Burke 1980). 
Game species have benefited from the creation of a great deal of edge and early-seral habitat and the use of dispersed cutting to reduce hydrologic and sediment production effects remains valid. However, these objectives are now being balanced against newer, landscape-level objectives (Harris 1984, Franklin and Forman 1987).

Criticism of the dispersed-cutting pattern generally focus on effects of "forest fragmentation": the large amount of high-contrast, forest-clearcut edge that is created and the rapid decline in the extent of interiorforest habitat. Remnant forest along these high-contrast edges suffers increased mortality due to windthrow (Ruth and Yoder 1953, Gratkowski 1956, Holtam 1971, DeWalle 1983, Savill 1983) and other processes (Rudinsky 1962, Franklin and Forman 1987). The altered microclimate of these edges also influences seedling establishment and competitive interactions between individual plants and results in changes in forest structure and composition (Saunders et al. 1991, Chen et al. 1992). Deleterious effects of edges on fauna, such as nest predation and brood parasitism on forest birds, are well documented in Eastern forests (Wilcove 1985, Wilcove et al. 1986, Noss 1991). Forest fragmentation in PNW forests is a much more recent phenomenon, and these effects have not yet been well documented (but see Rosenberg and Raphael 1986 and Lehmkuhl et al. 1991). Sharp declines in the extent of large blocks of interior old-growth forest have also raised serious concern for the survival of the Northern Spotted Owl (Strix occidentalis caurina), the Marbled Murrelet (Brachyramphus marmoratus) and other oldgrowth-dependent species (Gutiérrez and Carey 1985, Thomas et al. 1990, Johnson et al. 1991, Ruggiero et al. 1991, Noss 1993).

Several alternatives to dispersed cutting are currently under consideration in the PNW. Many of the alternatives are intended to modify timber harvesting practices at both the stand and landscape level so that they are more similar to the pre-settlement, wildfire-dominated, disturbance regime. These include reducing the area available for cutting by creating a network of large (20 000-50 000 ha) reserves (Thomas et al. 1990, Noss 1993), the use of longer rotation lengths (Johnson et al. 1991), and adopting a more aggregated distribution of cuts (Franklin and Forman 1987, Johnson et al. 1991, Swanson and Franklin 1992, Li et al. 1993). Here we consider the latter alternative: an aggregated-cutting process that reduces the amount of high-contrast edge habitat and retains larger blocks of interior forest habitat in the landscape. Most cutting on national forests in the PNW has been conducted during the last $40 \mathrm{yr}$, and on much of this land outside the protected wilderness areas, the first rotation of dispersed cutting is now 20-40\% complete (Ripple et al. 1991, Spies et al. 1994). On some national forests, $>70 \%$ of the land suitable for timber harvest has been cut (Morrison 1990). This historical activity has created a strong land- scape-level pattern legacy that may constrain future management decisions. If it is concluded that an aggregated distribution of cuts is more desirable, either for ecological or economic reasons, just how difficult will it be to transform the current landscape pattern into a new one?

Our objective here is not to focus on the ecological or economic consequences of these landscape patterns, but rather to examine the relationship between the disturbance rule set and the patterns that are created on the landscape. In particular, we focus on the lag in pattern change and the rule changes needed to transform a landscape from one pattern to another. We begin by comparing the landscape patterns created by dispersed- and aggregated-cutting rule sets in the absence of an initial pattern. We then initiate a series of simulations using the dispersed-cutting rule set and switch to the aggregated rule set at different points during the first rotation. Finally, we examine how the transformation from one landscape pattern to another is influenced by changes in the individual rules that govern the cutting process.

\section{MeTHODS \\ Model description}

Model structure and inputs. - This work uses a new simulation model for pattern development in forested landscapes. The model, CASCADE, builds on earlier modeling work by Franklin and Forman (1987), Li (1989), and Li et al. (1993). CASCADE operates on a simple gridded landscape and simulates landscape pattern dynamics in response to forest cutting and subsequent regrowth. Vegetation dynamics are not modeled directly (sensu Botkin et al. 1972, Shugart 1984, Smith and Urban 1988). Instead, forest regrowth is simply indexed as time since disturbance.

CASCADE is written in C and operates in a UNIX environment. The model requires two co-registered, gridded data layers and one auxiliary file as inputs to describe the study area and define initial conditions. Any size grid cell may be used. Selection of grid cell size represents a trade-off between accuracy in representation of the study area and computational limitations. The first data layer (AGE) provides the initial stand age for each grid cell. The second data layer (LHU) is a map of "Logical Harvest Units." Each LHU is a polygon constructed of many individual grid cells. All grid cells within a LHU are given the same identification number. The shape, size, and position of LHUs in the study area are defined by a forest engineer and incorporate regulatory and logistic constraints on road placement and log removal. These constraints are imposed primarily by topography and the location of the perennial stream network. The auxiliary input file (CENT) contains a listing of the LHU identification numbers and the $x, y$, grid cell coordinates for the centroid of each LHU. 
As cutting proceeds, individual LHUs are selected and cut completely; cutting only a portion of a unit is not permitted. Since the consequences (ecological, hydrological, or economic) of landscape pattern are not considered in this paper, the details of silvicultural treatments within units are not specified (i.e., clearcut, shelterwood, green-tree retention, etc.). It is sufficient for this analysis to specify that all units are cut using the same technique.

Cutting rules. - 1. Constraints on cutting. - For simulations using a dispersed distribution of cuts, adjacent units were not eligible for cutting during the same 10yr time step. This constraint is currently part of management practices on public forests in the PNW; however, it has not been widely applied on private land (US Forest Service 1990). This adjacency constraint was not applied to simulations using the aggregated distribution of cuts.

During each rotation, the entire planning area was cut once. Most of the simulations used a 100-yr rotation length. This rotation length dictated that $10 \%$ of the watershed was cut each decade and no units with an age $<100 \mathrm{yr}$ were eligible for cutting. In the final group of simulations, cutting rate and minimum age constraints were partially relaxed.

Simulations were conducted to examine the effect of rotation length on landscape pattern development. In addition to the 100-yr rotation length used in most of the other simulations, we included 50- and 200-yr rotation lengths with cutting rates of $20 \%$ and $5 \%$ of the watershed cut per decade and minimum cutting ages of 50 and $200 \mathrm{yr}$, respectively.

2. Spatial distribution of cuts. - The algorithm within CASCADE that generates either a dispersed or aggregated distribution of cuts is based on the use of a dispersion index developed by Clark and Evans (1954):

$$
R=2 p^{1 / 2} r,
$$

where $R$ is the dispersion index, $p$ is the mean patch density (number of patches per unit area), and $r$ is the mean nearest neighbor distance (see also Pielou 1977: 155). This dispersion index is widely used in ecological studies to provide a measure of the spatial distribution of objects. For a random arrangement of objects, $R=$ $1 ; R<1$ indicates an aggregated distribution of objects, while $R>1$ indicates a dispersed or uniform distribution of objects. In this study, nearest neighbor distances were calculated from the centroid of one cutting unit to the centroid of its nearest neighbor.

In all simulations, the initial unit to be cut was selected at random. To select each subsequent unit, all units eligible for cutting are examined and the unit that either maximizes (dispersed cutting) or minimizes (aggregated cutting) the dispersion index is selected as the next unit to be cut. As cutting proceeds, the dispersion index is calculated using only a prospective cutting unit and all "recently" cutover units (defined for most of our simulations as a unit with a stand age of $30 \mathrm{yr}$ or less). In forests on the west side of the Cascade Mountain Range, canopy closure usually occurs at $\approx 30 \mathrm{yr}$ after disturbance. Although there are important ecological differences between various age classes of closedcanopy forest, these differences are less striking than the contrast between open-canopy and closed-canopy forest (Hansen et al. 1991). For these simulations, closed-canopy forest is viewed as the matrix within which an archipelago of cuts is distributed. The cutting algorithm used here schedules the arrangement of this archipelago. After canopy closure at age 30 a cutover unit is treated as part of the matrix and its position is no longer considered when selecting new units for cutting. In one series of simulations we compare the effect of using canopy-closure ages of 20 and $40 \mathrm{yr}$.

Pattern description. - Although the model tracks changes in the stand age of each cutting unit in response to logging and stand regrowth, for simplicity in presentation of the results we distinguished only between open-canopy and closed-canopy stands. All simulations were run for three full rotations (300 yr for simulations that used a $100-y r$ rotation) with maps of the landscape output at the end of each 10-yr time step. A series of landscape indices was generated for each of these maps. Although dozens of indices are available for describing landscape pattern (O’Neill et al. 1988), we focus on two simple, ecologically significant measures: (1) density of edges (metres per hectare) between open- and closed-canopy forest; and (2) mean size (hectares) of interior, closed-canopy forest patches. Interior closed-canopy forest was defined as all closed-canopy forest $>100 \mathrm{~m}$ from the edge of a patch of open-canopy forest. Chen et al. (1992) have examined a range of biological and physical response variables along transects from recent clearcuts into intact, old-growth, Douglas-fir (Pseudotsuga menziesii) forest stands in Oregon and Washington. For some variables, measurable edge effects persist hundreds of metres from clearcut edges. They arbitrarily defined the depth-of-edge influence as the point at which a response variable returns to a condition representing two-thirds of the interior forest environment. Using this approach, they found depth-of-edge influence ranged from 0 to 137 $\mathrm{m}$. For this study we use $100 \mathrm{~m}$ as an overall estimate of the edge influence.

\section{Study area}

A 3827-ha landscape composed of two watersheds in the central Oregon portion of the Cascade Range was used for these simulations (Fig. 1). We digitized a LHU map of the study area using a $50 \times 50 \mathrm{~m}$ grid cell size. In the simulations, logging was prohibited in a $100 \mathrm{~m}$ wide buffer zone on each side of perennial streams. This buffer zone width is intermediate between current operational Forest Service guidelines (US Forest Service 1990) and recent recommendations that are intended to aid in the restoration of anadromous fish populations (Johnson et al. 1991). LHUs for this 


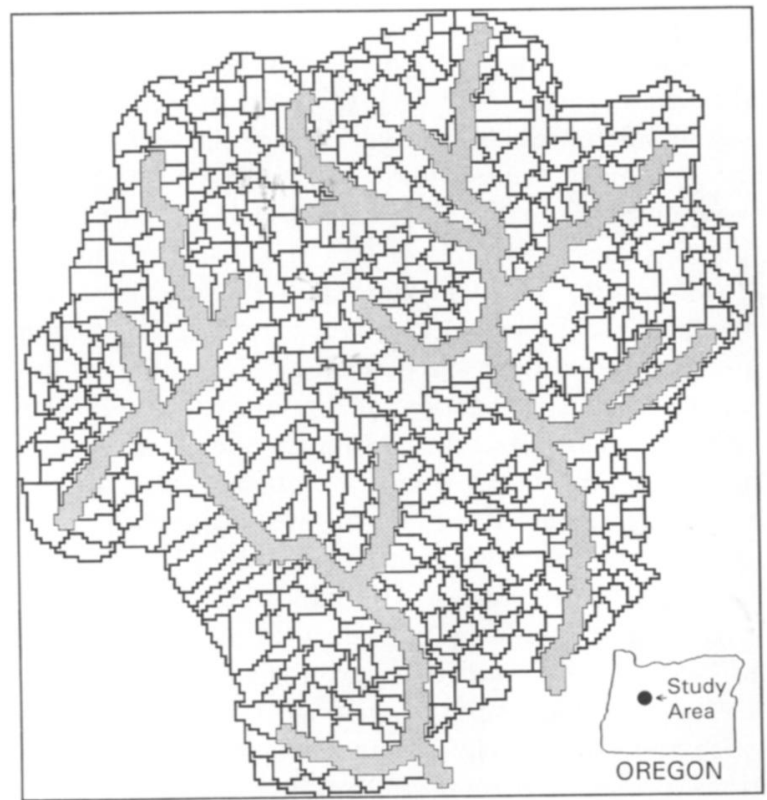

Fig. 1. Cutting unit map of the Cooke-Quentin watershed in the west-central Oregon Cascade mountain range (Blue River Ranger District of the Willamette National Forest). Shaded area represents riparian zones, which are not eligible for cutting. Other polygons represent logical harvest units (see Methods: Model structure and inputs).

watershed were originally defined using a somewhat narrower riparian buffer zone. Use of the 100-m buffer zone here greatly reduced the size of some of the streamside LHUs. In practice, some of these smaller units would probably be absorbed into adjacent units, however, this adjustment would not have a substantive impact on our results. For the LHU map used here, sizes range from 0.75 to 37.25 ha with an average size of 7.4 ha.

\section{Simulations}

In order to focus on the process of pattern development, all simulations were initiated on a landscape with no pattern; that is, at time zero the entire watershed was initialized to a stand age that was eligible for cutting. Three sets of simulations were conducted. These simulations were intended to: (1) compare the landscape patterns that developed using either the dispersed or the aggregated-cutting rule sets; (2) examine landscape pattern response when the cutting rule set was switched from dispersed to aggregated at different points during the first rotation (i.e., at different stages of development of a dispersed pattern); and (3) determine how a relaxation of the constraints to cutting (cutting rate, minimum cutting age) influenced the pattern that developed after switching from a dispersed to an aggregated-cutting rule set.

The first set of simulations was used to compare pattern development using a range of different canopyclosure ages and rotation lengths. The first subset of simulations used a 100 -yr rotation length and canopyclosure ages of 20,30, and 40 yr. For each canopyclosure age, five pairs of simulations were conducted. Each pair of simulations began using a different randomly selected initial LHU. After cutting this randomly selected initial unit, each pair of simulations included one run that proceeded using the dispersed-cutting rule set and another that used the aggregated-cutting rule set. These same five randomly selected initial LHUs were used to initiate all subsequent replicate runs. The second subset of simulations used a canopy-closure age of $30 \mathrm{yr}$ and rotation lengths of 50 and $200 \mathrm{yr}$. For each rotation length, five pairs of simulations were conducted; one run used dispersed cutting, while the other used aggregated cutting.

All runs in the second set of simulations were based on the use of a 100-yr rotation length and a canopyclosure age of $30 \mathrm{yr}$. All runs were initiated using dispersed cutting and then switched to aggregated cutting after 20,40 , or $60 \mathrm{yr}$. Five replicate simulations were conducted for each of these three transition times.

The third set of simulations also used a 100-yr rotation length and a canopy-closure age of $30 \mathrm{yr}$. All runs were again initiated using dispersed cutting and a switch to aggregated cutting after $50 \mathrm{yr}$. After making the switch, one of the constraints to cutting was relaxed. The first subset of simulations involved reducing the minimum cutting age constraint from 100 to $50 \mathrm{yr}$. On federal lands in the PNW, harvesting stands with an age of $<50 \mathrm{yr}$ is not generally considered ecologically or economically prudent. In these simulations, this reduced minimum cutting age was maintained for 20 , 60 , or $100 \mathrm{yr}$. Five replicate simulations were conducted for each of these periods. The second subset of simulations involved reducing the cutting rate for a period of $50 \mathrm{yr}$. After the switch to aggregated cutting, the cutting rate was reduced from $10 \%$ of the study area per decade to 0,4 , or $8 \%$ per decade. Five replicate simulation runs were conducted for each of these cutting rates.

\section{RESULTS}

\section{Pattern development}

The landscape patterns that developed for one pair of simulations during the first $80 \mathrm{yr}$ are illustrated in Fig. 2. This pair of simulations used a canopy-closure age of $30 \mathrm{yr}$ and a rotation length of $100 \mathrm{yr}$. The dispersed-cutting rule set rapidly produced and then maintained a landscape with an edge density more than twice as high as that produced using an aggregatedcutting rule set (Fig. 3a). Similarly, the mean size of interior, closed-canopy forest patches was quite different under dispersed and aggregated-cutting rule sets (Fig: 3b). Among the five replicate simulations using the dispersed-cutting rule set and among the five replicates using the aggregated rule set, the variation at any given simulation time step is very small. This vari- 

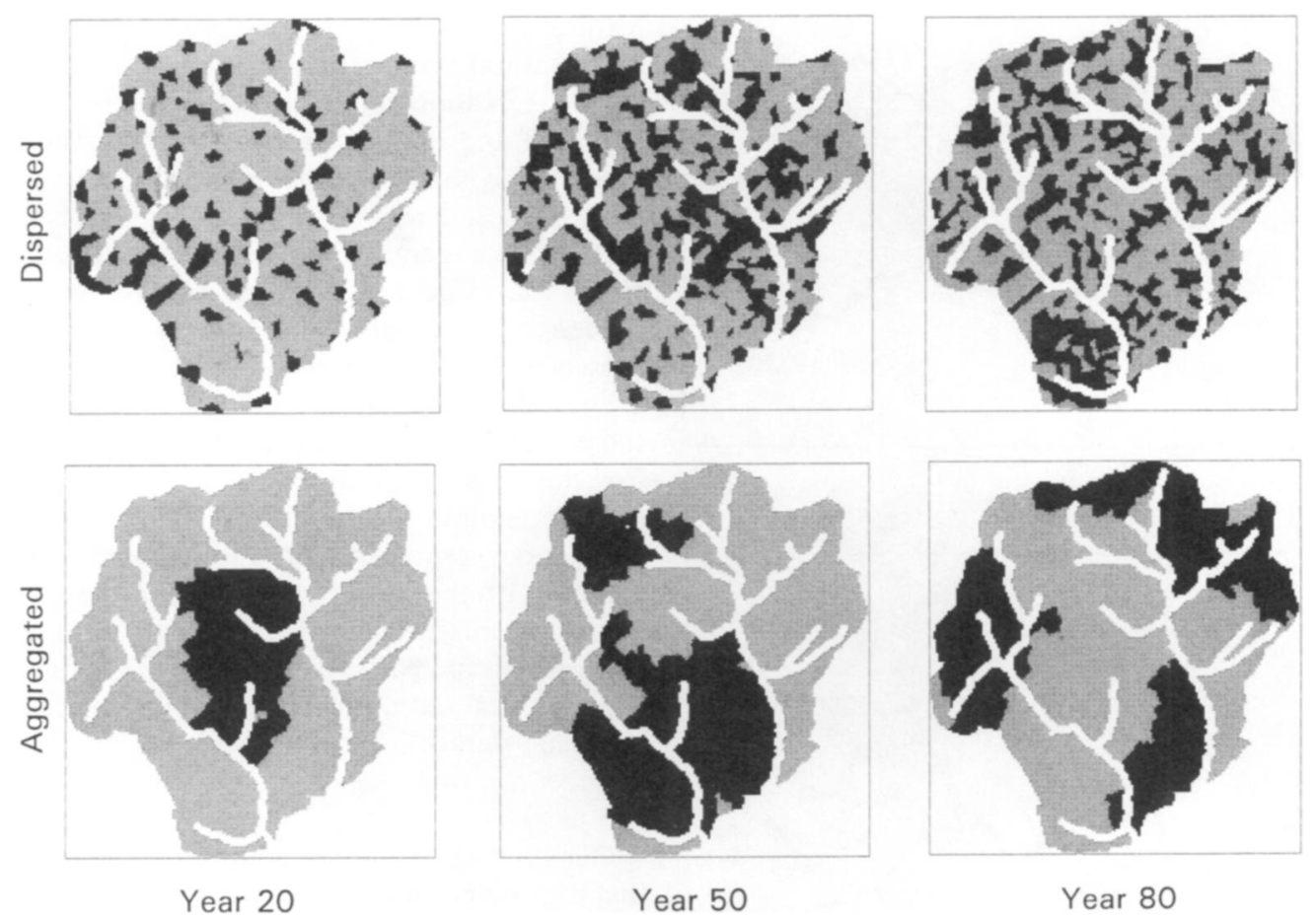

Fig. 2. Landscape pattern development for one pair of simulations comparing the dispersed and aggregated-cutting plans. Black represents recently cut units; shaded represents closed-canopy forest; white areas are riparian zones.

ation is caused by the different, randomly selected, initial cutting unit used for each replicate. Since the variance among replicates is so small, and remained small for all subsequent model runs, in the remaining graphs we present only the mean response curves.

The mean response curves for simulations using a 100 -yr rotation length and canopy-closure ages of 20 , 30 , and 40 yr were essentially parallel (Fig. 4). Similarly, the mean response curves for simulations using a canopy-closure age of $30 \mathrm{yr}$ and rotation lengths of 50,100 , and $200 \mathrm{yr}$ were also essentially parallel (Fig. 5). Neither canopy-closure age nor rotation length had much effect on the difference between the response curves for landscapes generated using dispersed or aggregated cutting. Regardless of canopy-closure age or rotation length, dispersed cutting results in a much higher edge density and a much lower mean interior forest patch size than when aggregated cutting is used.

For all simulations presented here, the riparian zones were treated as "background," i.e., areas of closed canopy forest were treated as discrete patches if separated by a riparian zone. Additional model runs were also conducted (results not presented here) without riparian corridors or with the riparian corridors treated as "connectors" between patches of closed canopy forest. In these simulations, the differences between landscape pattern generated by dispersed and aggregated-cutting rule sets were comparable to those presented here. Results (not presented) were also comparable when sim- ulations were conducted using a LHU map from another study area.

\section{Pattern response to switch in cutting rule set}

Switching from a dispersed- to an aggregated-cutting rule set produced little change in landscape pattern (Fig. 6). Even after only $20 \mathrm{yr}$ of dispersed cutting, this switch in the cutting process produced only a small change in the landscape pattern, as reflected in the edge density and the mean size of interior forest patches. A switch after 40 or 60 yr produced even less change in landscape pattern.

\section{Pattern response to change of individual rules}

Relaxing the minimum cutting age constraint resulted in only a partial change in landscape pattern (Fig. 7); however, this change was slightly greater than that obtained without easing this constraint (Fig. 6). The length of time that this constraint is relaxed has a relatively small effect on the results.

Reduction of the cutting rate resulted in a greater change in landscape pattern (Fig. 8). A complete moratorium on cutting ( $0 \%$ of watershed cut per decade) for $50 \mathrm{yr}$ resulted in the largest change in landscape pattern. After this moratorium, edge density was nearly as low as for the simulations initiated using the aggregated-cutting algorithm. The moratorium also resulted 

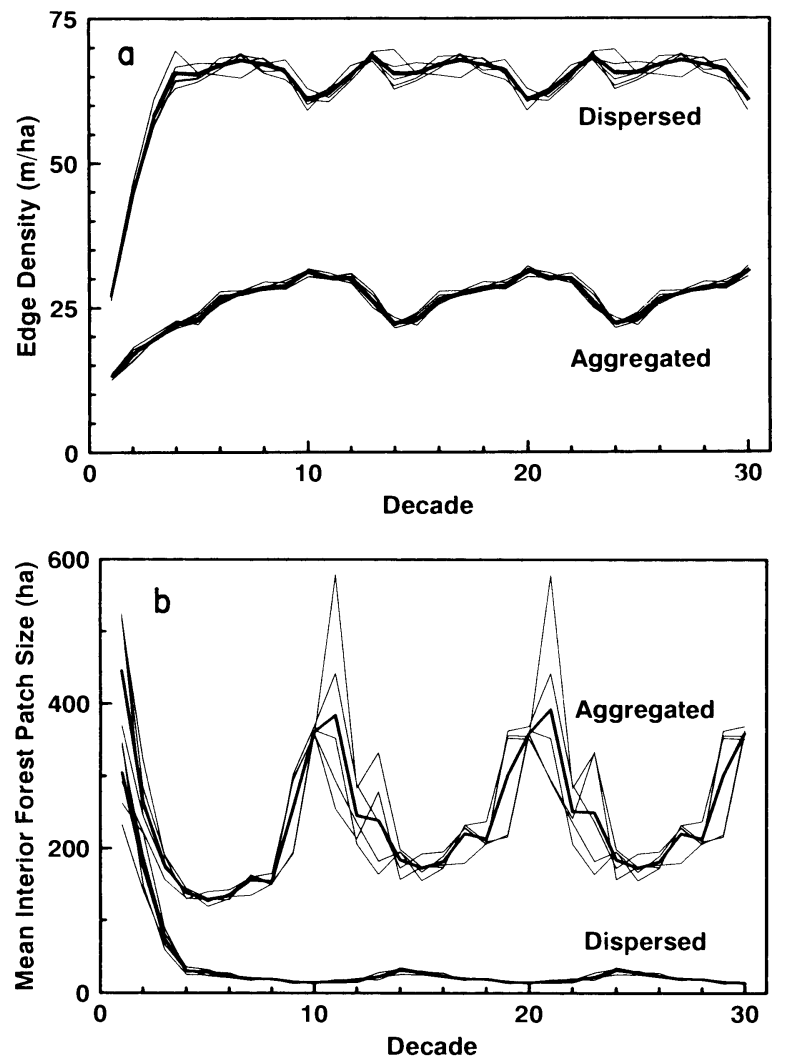

FIG. 3. 300-yr simulations using dispersed- or aggregatedcutting rule set. All runs used a $100-y r$ rotation length $(10 \%$ of area cut per decade) and a canopy-closure age of $30 \mathrm{yr}$. Thick lines represent the mean of five replicates. Thin lines represent response curves for each replicate. (a) Density of edges between open and closed-canopy forest; (b) Mean size of interior closed-canopy forest patches.

in the largest increase in mean patch size of interior, closed-canopy forest. This increase in mean patch size was accompanied by a striking increase in the temporal variability in patch size. At times, mean patch size greatly exceeded values for simulations initiated using the aggregated-cutting rules; during most time steps, however, forest patches were only about half the size of those created in simulations initiated using the aggregated-cutting rules. A relatively modest reduction in the cutting rate to $8 \%$ per decade resulted in a substantial reduction in edge density, but only a small change in mean interior forest patch size.

\section{Discussion}

Following a wildfire, surviving trees, snags, and coarse woody debris from the previous stand are incorporated into the subsequent stand. This structural legacy contributes a great deal to the complexity of young natural stands (Franklin et al. 1981, Spies et al. 1988, Hansen et al. 1991). Following a traditional clearcut, little or no structural legacy is retained from the previous stand, and this lack of structural complexity is one of the main features that distinguish managed stands (plantations) from natural stands (Franklin et al. 1981, Hansen et al. 1991). Although the ecological differences between managed and natural stands are important, we have chosen to ignore these differences for the purposes of our analyses. Our analyses have focused on the differences, at comparable points in the cutting cycle, between landscape patterns generated by various cutting processes. We recognize that, as a result of the declining presence of natural forest over the first rotation, conditions that exist during the first rotation are unlike those that will exist throughout subsequent rotations. For this reason, comparisons between landscapes at different points in the cutting cycle, with different amounts of residual natural forest, could be very misleading with the simple landscape metrics used in this study. An analysis of the ecological consequences of these landscape patterns will require consideration of the structural characteristics of the various natural and managed stands in the landscape.

\section{Pattern development}

Our preliminary series of simulations demonstrate that canopy-closure age and rotation length have little effect on the difference between landscape patterns generated by dispersed or aggregated-cutting rule sets (Figs. 4 and 5, respectively). The values of both landscape metrics were somewhat different when different canopy-closure ages and rotation lengths were used; however, the differences between the landscape metrics generated by these two cutting plans remained comparable. Since we were primarily interested in these differences rather than the absolute value of any given landscape metric, we chose to use a canopy-closure age of $30 \mathrm{yr}$ and a rotation length of $100 \mathrm{yr}$ for the balance of our simulations.

The results of our analyses of landscape patterns generated using either the dispersed or aggregated-cutting rule sets are consistent with the earlier results from Franklin and Forman (1987), Li (1989), and Li et al. (1993). However, our results extend their findings by providing a more complete picture of the dynamics of landscape pattern through multiple rotations and by examining pattern inertia when cutting rules are changed. These earlier studies focused on the conversion of natural forests to managed forests and chose to ignore stand regrowth. Their simulations were initiated with landscapes composed entirely of natural forest and their analyses documented the elimination of these natural forests. In order to deal with multiple rotations in our simulations, we included stand regrowth by indexing time since logging and we ignored the differences between natural forests and managed stands over $30 \mathrm{yr}$ of age. Because we chose to include stand regrowth, comparisons between our results and the earlier studies are valid only through year 40 . At this point, when using a canopy-closure age of $30 \mathrm{yr}$, stand regrowth becomes important and our results begin to 

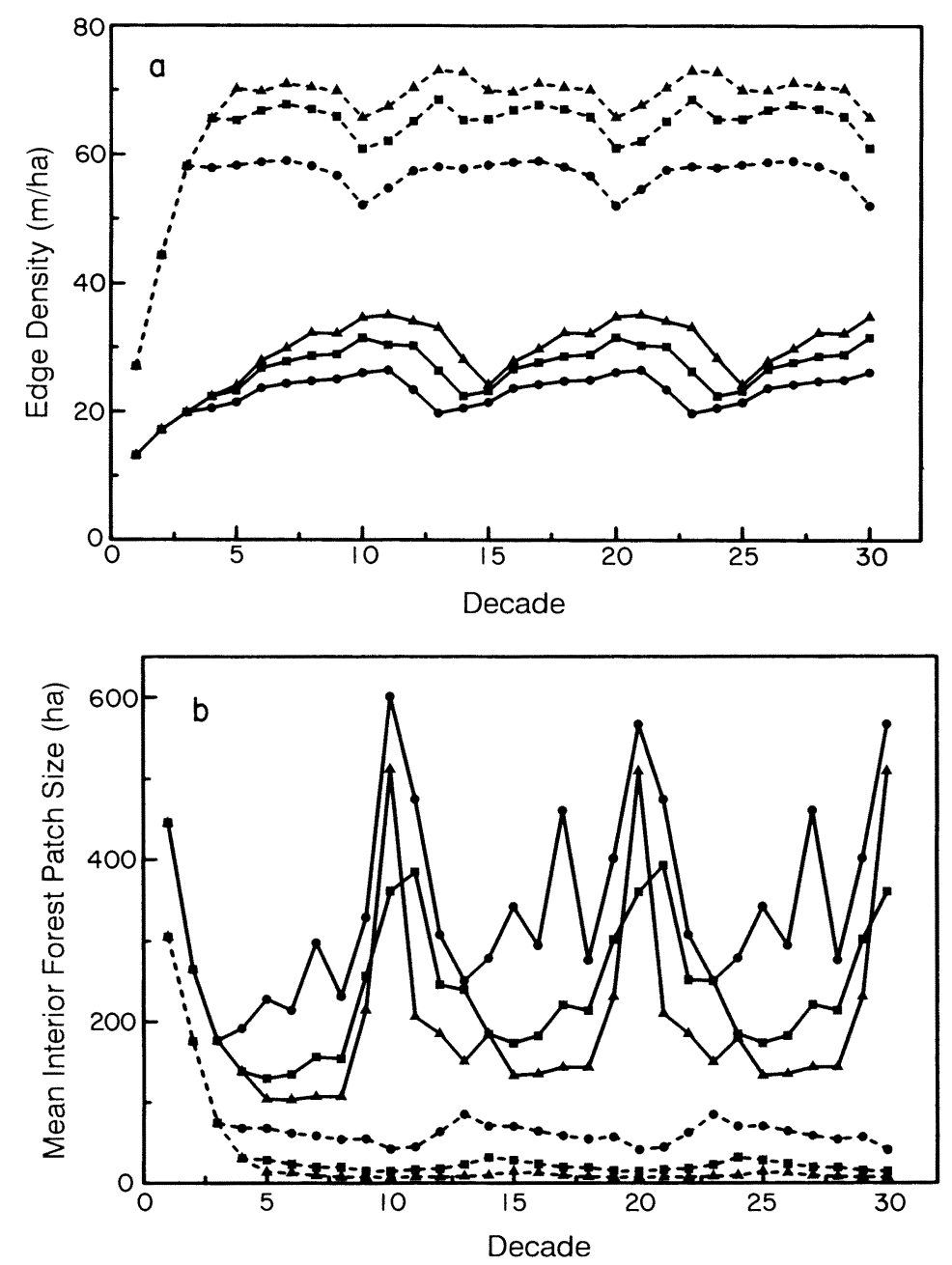

Fig. 4. Effect of canopy-closure age. 300-yr simulations using dispersed (-- $)$ or aggregated ( $\longrightarrow$ ) cutting rule sets and a 100 -yr rotation length (cutting rate of $10 \%$ per decade). Canopy-closure ages are $20(\bullet), 30(\square)$, and 40 (৫) yr. (a) Edge density; (b) mean interior closed-canopy forest patch size.

diverge from those of Franklin and Forman (1987), Li (1989), and $\mathrm{Li}$ et al. (1993). These earlier studies did not deal with time directly. Instead, they indexed their simulations based on the percentage of the landscape that had been cut-much the same as the percentage of rotation length index used in our Fig. 5. For the 100yr rotation length used in most of our simulations, year 40 corresponds to $40 \%$ of the landscape cut. For the dispersed-cutting plan, our results show edge density leveling off at year 40 , while the earlier studies show a continued increase until year 50 (50\% of the landscape cut), followed by a steady decline as the remaining natural forest is removed. In each of our scenarios, the total area of interior closed-canopy forest stabilizes after year 40 . However, the aggregated-cutting rule set produces very high variation in mean patch size over time (Figs. $3 b, 4 b$, and $5 b$ ). This temporal variation occurs as large patches are fragmented and merged in response to cutting and forest regrowth. This variabil- ity is a fundamental characteristic of any aggregated disturbance process. In contrast, for the dispersed-cutting rule set, we found that both landscape metrics used here remained fairly constant through the balance of the simulations. This difference in the temporal variability of patch size seems likely to have important consequences for many ecological phenomena. This variability may provide periodic windows of opportunity for gene flow between populations restricted to interior closed-canopy forest, and it may also influence the propagation of disturbance events such as fire and insect outbreaks.

The temporal patterns of variation in edge density and mean patch size are identical during the second and third rotations (Fig. 3; decades 10 through 20 and 20 through 30, respectively). This pattern repeats indefinitely and is caused by the deterministic rule sets used in these simulations. With the minimum stand age eligible for cutting set to a value identical to the 

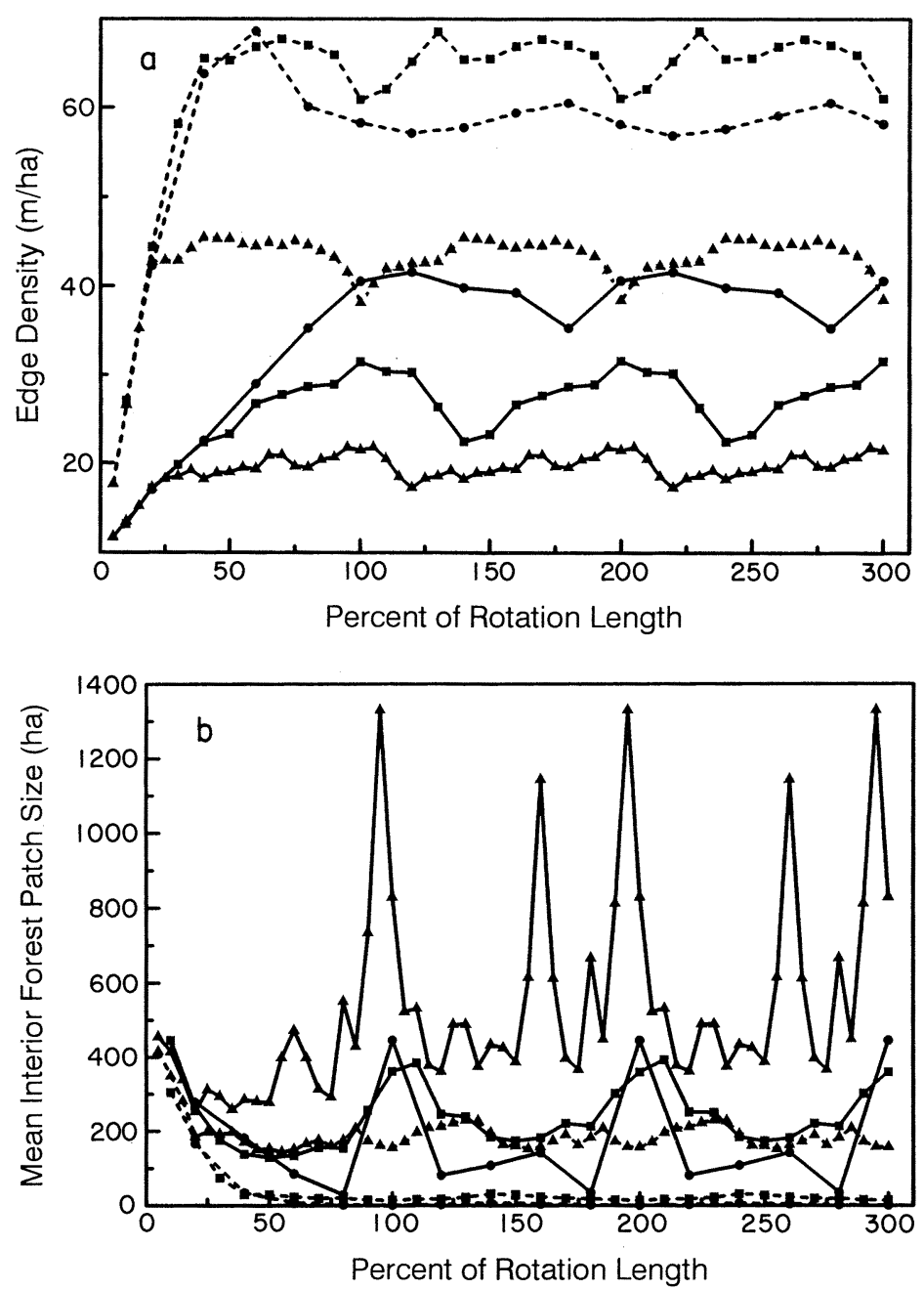

FIG. 5. Effect of rotation length. 300-yr simulations using dispersed (-- ) or aggregated $(-)$ cutting rule sets and a canopy-closure age of $30 \mathrm{yr}$. Note that the $x$ axes are normalized to percent of rotation length to facilitate comparisons among the different rotation lengths. Rotation lengths/cutting rates (\% area cut per decade) are $50 \mathrm{yr} / 20 \%(\bullet), 100 \mathrm{yr} / 10 \%$ (口) and $200 \mathrm{yr} / 5 \%$ ( $\mathbf{\Lambda})$ years. (a) Edge density; (b) mean interior closed-canopy forest patch size.

rotation length, the scheduling of cuts becomes locked in, in perpetuity, by the end of the first rotation. During the first time step of the second rotation, the only LHUs old enough to be cut again are the same ones cut during the first time step of the first rotation. The same is true for all subsequent time steps. More flexibility in the scheduling of cuts could be introduced only by easing the minimum cutting age or cutting rate constraints and by using a less rigidly defined spatial distribution of cuts. Instead of selecting cutting units that maximize or minimize the dispersion index, cutting units could be selected that result in a dispersion index that is somewhat less than the maximum or somewhat greater than the minimum possible value.

All simulations presented here are based on a LHU map from a single study area; however, the results were comparable when using a LHU map from another watershed (results not presented). The shape and size of
LHUs are defined primarily by the constraints imposed by topography and other factors on log removal from the cutting units. In the steep and highly dissected terrain of this region, steel cables are used to move logs out of the cutting unit to a landing where they can be loaded onto trucks. These cable-yarding systems, and other factors, dictate that the shapes of the individual LHUs are quite simple (low fractal index) and the range of sizes is limited by past trade-off decisions among ecologic, economic, and engineering considerations. Hence, the shape and size of individual LHUs is similar among watersheds. The LHU map would also have been similar if it had been developed with the intention of using an aggregated-cutting plan (J. Cissel, personal communication). Since the primary focus of this study is on how historic cutting practices constrain future landscape patterns, we chose to use cutting unit sizes for our simulations that are comparable to those used 
on federal lands over the past 40 yr. Franklin and Forman (1987) and Li et al. (1993) have examined the effect of cutting unit size on landscape pattern. They found that as cutting unit size increases, there is a gradual decrease in the difference between landscape patterns generated by dispersed or aggregated cutting (what they referred to as "checkerboard" vs. "progressive parallel"). The difference between landscape patterns generated by dispersed and aggregated cutting should remain substantial until cutting unit size approaches the total area cut for each time step.

Roads were not dealt with explicitly in these simulations, although constraints imposed by road placement were a major factor in the development of the LHU map. Our simulations implicitly assume that each road segment is constructed when needed to access the next LHU selected for cutting. During the initial stages of timber harvesting in a previously unroaded watershed, the dispersion of cuts can be limited by economic constraints on development of a road system. In most
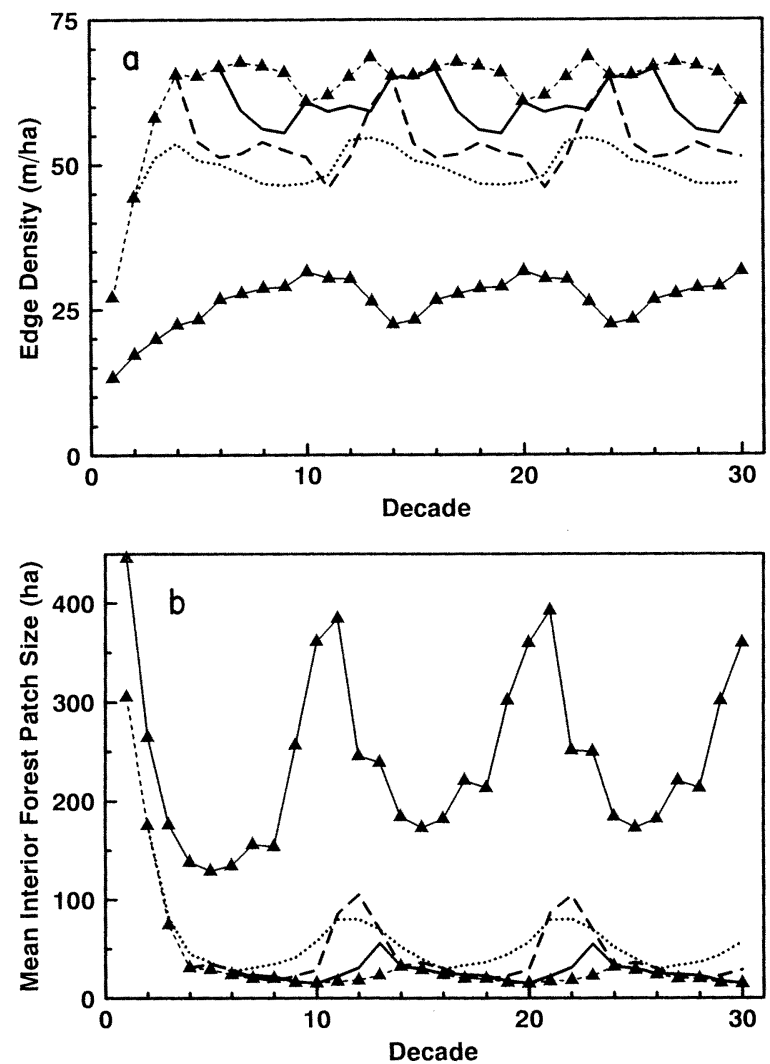

FIG. 6. 300-yr simulations using a 100-yr rotation length (cutting rate of $10 \%$ per decade) and a canopy-closure age of $30 \mathrm{yr}$. All runs were initiated using the dispersed-cutting rule set and then switched to the aggregated-cutting rule set after $20(\cdots \cdots), 40(---)$, or $60(-)$ yr of cutting. Each line represents the mean of five replicates. Mean response curves for $300 \mathrm{yr}$ of dispersed $\left(---\mathbf{-}_{---}\right)$and aggregated (- - ) cutting (from Fig. 3) are included for comparison. (a) Edge density; (b) mean interior closed-canopy forest patch size.
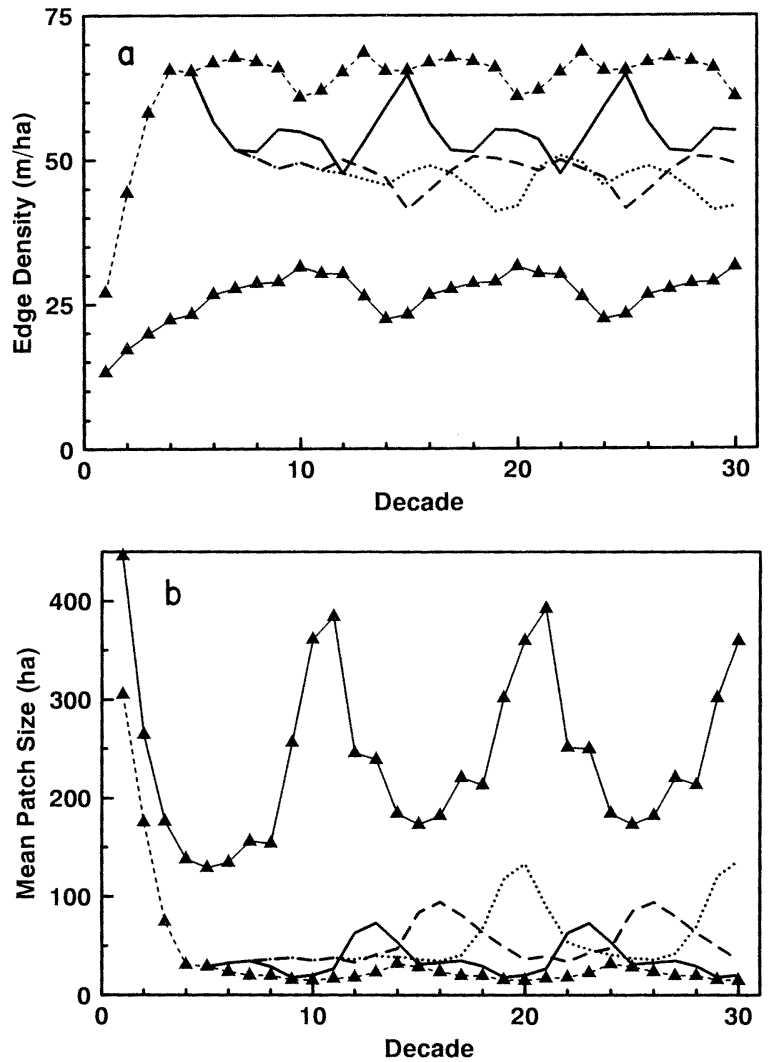

FIG. 7. Effect of a temporary reduction in the minimum cutting age for $300-\mathrm{yr}$ simulations initiated using the dispersed-cutting rule set and then switched to the aggregatedcutting rule set after $50 \mathrm{yr}$ of cutting. Rotation length is 100 yr (cutting rate of $10 \%$ per decade) and a canopy-closure age of $30 \mathrm{yr}$. After the switch, stands $\geq 50 \mathrm{yr}$ of age were eligible for cutting for a period of $20(-), 60(---)$, or $100(\cdots)$ ) yr. Each line represents the mean of five replicates. Mean response curves for $300 \mathrm{yr}$ of dispersed (-- $-4---)$ and aggregated (- $\longrightarrow$ ) cutting (from Fig. 3) are included for comparison. (a) Edge density; (b) mean interior closed-canopy forest patch size.

cases, it is possible to gain access to a watershed from several directions, and this makes it possible to disperse the initial cuts to a substantial degree. Li et al. (1993) found that constraints imposed by road construction did reduce the dispersion of cuts. This was reflected in a lower edge density and higher amounts of interior forest habitat relative to the pattern generated by maximally dispersed cutting. Even with these road construction constraints, there was a substantial, albeit somewhat smaller, difference between the landscape patterns generated by dispersed vs. aggregated cutting (what they referred to as "staggered-setting" and "progressive cutting," respectively). Road construction was not included as a constraint in any of our simulations. Had it been included, the results of $\mathrm{Li}$ et al. (1993) suggest that our results would not have been substantively different. 

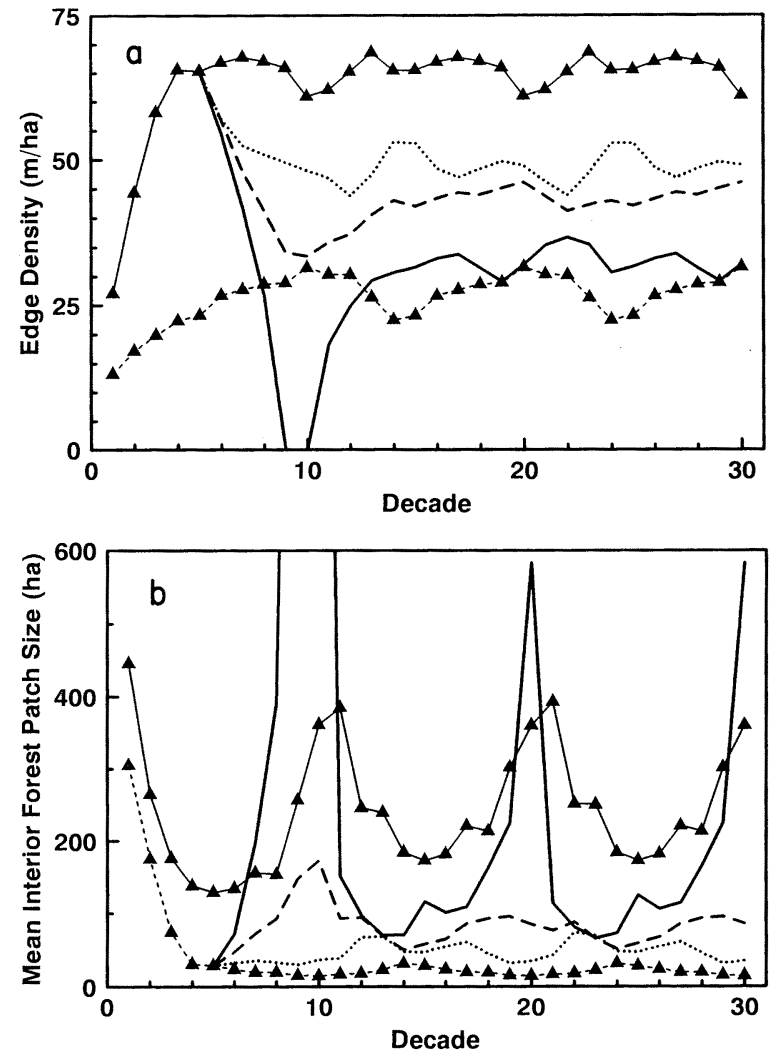

Fig. 8. Effect of a temporary reduction in the cutting rate for 300 -yr simulations initiated using the dispersed-cutting rule set and then switched to the aggregated-cutting rule set after $50 \mathrm{yr}$ of cutting. Canopy-closure age is $30 \mathrm{yr}$. After the switch, the cutting rate was reduced from $10 \%$ of the watershed per decade to $0 \%(-), 4 \%(---)$, or $8 \%(\cdots)$ ) of the watershed per decade for a period of $50 \mathrm{yr}$. Each line represents the mean of five replicates. Mean response curves for $300 \mathrm{yr}$ of dispersed $\left(---\Delta_{-}--\right)$and aggregated $(-\Delta-)$ cutting (from Fig. 3) are included for comparison. (a) Edge density; (b) mean interior closed-canopy forest patch size.

\section{Modifying landscape pattern}

If dispersed cutting is abandoned on federal lands in the PNW, our results indicate that it will not be easy to erase the pattern legacy created by past forest cutting practices. Regardless of the canopy-closure age or rotation length, the difference between the landscape pattern created by dispersed and aggregated-cutting plans was comparable (Figs. 4 and 5). Even after only $20 \mathrm{yr}$ of dispersed cutting, a pattern is well established on the landscape (Figs. 2 and 6). Cuts made during these first few decades are not eligible for cutting again until they reach an age of $100 \mathrm{yr}$ under the rules used in these simulations. It is necessary to work around these early cuts, and this has the effect of reinforcing the early pattern. Erasing this pattern and establishing a new one requires a substantial change in the individual rules (constraints) that govern the cutting process.

Easing the constraints on minimum cutting age or reducing the cutting rate improves the transition from a dispersed to an aggregated landscape pattern (Figs. 7 and 8). Although the rule change scenarios presented here do not represent the only changes that could be implemented, they do provide reasonable examples of the type of management options that could be implemented in an effort to modify existing landscape patterns. Our results indicate that landscape pattern is more sensitive to changes in cutting rate than to changes in the minimum cutting age. None of the rule change scenarios tested here were completely successful in transforming the landscape pattern. A complete transformation of landscape pattern would require implementation of more extreme changes in the cutting rules. These include a 100-yr moratorium on cutting after the switch from dispersed to aggregated cutting, or the combination of a long moratorium and an extended reduction in the minimum cutting age.

The dispersed- and aggregated-cutting plans presented here represent a limited sample of the potential forest management options. There is a range of other options between these two end points, and many variations on these two themes, that were not included in our analysis. Nevertheless, the "maximum-dispersal" algorithm used here produces landscape patterns that seem to be comparable to the real landscape patterns that have been produced by logging on federal land. If comparisons are made between landscapes produced using a less aggregated and a less dispersed cutting plan, it seems likely that the differences will be less extreme than those reported here. It also seems likely that it will be easier to transform the landscape patterns created using these less extreme cutting plans. Although the spatial distribution of many natural disturbance events follows these two basic patterns, few natural processes are governed by such rigidly deterministic rule sets (Pickett and White 1985). Nevertheless, the use of simple models can often be enlightening (May 1989).

Disturbances other than those that are part of the management plan are also likely to affect landscape pattern, in some cases resetting landscape pattern and in other cases sustaining it. The effect of these additional processes (e.g., windthrow, wildfire) will be a function of the scale of these processes relative to the scale of the management activities and the type and degree of interaction between the management activities and the additional disturbance processes. Very extensive wildfire, for example, may overprint a landscape of smaller patches created by cutting, thus creating opportunity to develop new landscape patterns after the forest has regrown to the point of cutting again. Some disturbances may amplify landscape pattern without changing the basic pattern. This may occur as a result of selective attack by insects on young age class patches that reinitializes vegetation succession in these patches. Other disturbances may cause modification of the intended pattern. This can occur when disturbances preferentially affect older vegetation at the edges of a 
managed paich. These effects would foster increased aggregation of young age class patches even though the management plan may be designed to develop a dispersed pattern.

Our results demonstrate that some landscape-level patterns are highly resistant to change when driven by deterministic disturbance processes governed by simple rules. The legacy of landscape patterns can persist long after a fundamental change in the rules governing these disturbance processes. Hence, pattern analysis may provide only limited information about changes in these disturbance rules. In the simulations presented here, the switch from a dispersed- to an aggregatedcutting rule, by itself, was not enough to result in a substantial pattern change (Fig. 6). A partial shift in landscape pattern occurred only when the change in the spatial distribution of cuts was accompanied by a change in the rules that constrain the cutting process (e.g., change in which age classes are susceptible to disturbance, Fig. 7; reduction in disturbance rate, Fig. 8). This is an important result that may also apply to a wide range of anthropogenic and natural disturbance processes.

\section{ACKNOWLEDGMENTS}

We thank Larry Peterson, Blue River Ranger District of the Willamette National Forest for providing the LHU map for our study area. Funding for this work was provided by the USDA Forest Service New Perspectives Program and the National Sciences Foundation through the H. J. Andrews Long-Term Ecological Research (LTER) site (Grant 90-11663). L. Carlson, J. Cissel, S. Garman, A. Hansen, J. Jones, M. Turner, D. Urban, and two anonymous reviewers provided very useful comments on earlier drafts of this manuscript. This is Paper 2926 of the Forest Research Laboratory, Oregon State University.

\section{Literature Cited}

Bormann, F. H., and G. E. Likens. 1979. Pattern and process in a forested ecosystem. Springer-Verlag, New York, New York, USA.

Botkin, D. B., J. F. Janak, and J. R. Wallis. 1972. Some ecological consequences of a computer model of forest growth. Journal of Ecology 60:849-873.

Burke, C. J. 1980. Historic fires in the central western Cascades, Oregon. Thesis. Oregon State University, Corvallis, Oregon, USA.

Cale, W. G., G. M. Henebry, and J. A. Yeakley. 1989. Inferring process from pattern in natural communities. BioScience 39:600-605.

Chen, J., J. F. Franklin, and T. A. Spies. 1992. Vegetation response to edge environments in old-growth Douglas-fir forests. Ecological Applications 2:387-396.

Clark, P. J., and F. C. Evans. 1954. Distance to nearest neighbor as a measure of spatial relationships in populations. Ecology 35:445-453.

DeWalle, D. R. 1983. Wind damage around clearcuts in the ridge and valley province of Pennsylvania. Journal of Forestry 81:158-159.

Franklin, J. F., K. Cromack, W. Denison, A. McKee, C. Maser, J. Sedell, F. Swanson, and G. Juday. 1981. Ecological characteristics of old-growth Douglas-fir forests. US Forest Service General Technical Report PNW-GTR-118.
Franklin, J. F., and R. T. T. Forman. 1987. Creating landscape patterns by forest cutting: ecological consequences and principles. Landscape Ecology 1:5-18.

Gratkowski, H. J. 1956. Windthrow around staggered settings in old-growth Douglas-fir. Forest Science 2:60-74.

Gutiérrez, R. J., and A. B. Carey, editors. 1985. Ecology and management of the spotted owl in the Pacific Northwest. US Forest Service Pacific Northwest Forest and Range Experiment Station General Technical Report, PNW-GTR185.

Hansen, A. J., T. A. Spies, F. J. Swanson, and J. L. Ohmann. 1991. Conserving biodiversity in managed forests. BioScience 41:382-392.

Harris, L. D. 1984. The fragmented forest. University of Chicago Press, Chicago, Illinois, USA.

Holtam, B. W., editor. 1971. Windblow of Scottish forests in January 1968. Bulletin of the British Forestry Commission 45.

Johnson, K. N., J. F. Franklin, J. W. Thomas, and J. Gordon. 1991. Alternatives for management of late-successional forests of the Pacific Northwest: a report to the agricultural committee and the merchant marine and fisheries committee of the US House of Representatives. Unpublished Report to the House of Representatives, 8 October 1991. Washington, D.C., USA.

Lehmkuhl, J. F., L. F. Ruggiero, and P. A. Hall. 1991. Landscape-scale patterns of forest fragmentation and wildlife richness and abundance in the southern Washington Cascade range. Pages 425-442 in L. F. Ruggiero, K. B. Aubry, A. B. Carey, and M. H. Huff, technical coordinators. Wildlife and vegetation of unmanaged Douglas-fir forests. US Forest Service Pacific Northwest Research Station General Technical Report PNW-GTR-285.

Li, H. 1989. Spatio-temporal pattern analysis of managed forest landscapes: a simulation approach. Dissertation. Department of Forest Science, Oregon State University, Corvallis, Oregon, USA.

Li, H., J. F. Franklin, F. J. Swanson, and T. A. Spies. 1993. Developing alternative forest cutting patterns: a simulation approach. Landscape Ecology 8:63-75.

May, R. M. 1989. Detecting density dependence in imaginary worlds. Nature 338:16-17.

McIntosh, R. P. 1985. The background of ecology. Cambridge University Press, Cambridge, England.

Mooney, H. A., and M. Godron, editor. 1983. Disturbance and ecosystems. Springer-Verlag, New York, New York, USA.

Morrison, P. H. 1990. Ancient forests on the Olympic National Forest: analysis from a historical and landscape perspective. The Wilderness Society, Washington, D.C., USA.

Noss, R. F. 1991. Effects of edge and internal patchiness on avian habitat use in an old-growth Florida hammock. Natural Areas Journal 11(1):34-47.

1993. A conservation plan for the Oregon Coast Range: some preliminary suggestions. Natural Areas Journal 13:276-290.

O’Neill, R. V., J. R. Krummel, R. H. Gardner, G. Sugihara, B. Jackson, D. L. DeAngelis, B. T. Milne, M. G. Turner, B. Zygmunt, S. W. Christensen, V. H. Dale, and R. L. Graham. 1988. Indices of landscape pattern. Landscape Ecology 1:153-162.

Paine, R. T., and S. A. Levin. 1981. Intertidal landscapes: disturbance and the dynamics of pattern. Ecological Monographs 51:145-178.

Pickett, S. T. A., and P. S. White, editors. 1985. The ecology of natural disturbance and patch dynamics. Academic Press, New York, New York, USA.

Pielou, E. C. 1977. Mathematical ecology. Wiley, New York, New York, USA.

Ripple, W. J., G. A. Bradshaw, and T. A. Spies. 1991. Mea- 
suring forest landscape patterns in the Cascade range of Oregon, USA. Biological Conservation 57:73-88.

Rosenberg, K. V., and M. G. Raphael. 1986. Effects of forest fragmentation on vertebrates in Douglas-fir forests. Pages 263-272 in J. Verner, M. L. Morrison, and C. J. Ralph editors. Wildlife 2000: modeling habitat relationships of terrestrial vertebrates. University of Wisconsin Press, Madison, Wisconsin, USA.

Rudinsky, J. A. 1962. Ecology of Scolytidae. Annual Reviews of Entomology 7:327-347.

Ruggiero, L. F., K. B. Aubry, A. B. Carey, and M. H. Huff, technical coordinators. 1991. Wildlife and vegetation of unmanaged Douglas-fir forests. US Forest Service Pacific Northwest Research Station General Technical Report PNW-GTR-285.

Ruth, R. H., and R. A. Yoder. 1953. Reducing wind damage in the forests of the Oregon coast range. US Forest Service Pacific Northwest Forest and Range Experiment Station Research Paper 7.

Saunders, D. A., R. J. Hobbs, and C. R. Margules. 1991. Biological consequences of ecosystem fragmentation: a review. Conservation Biology 5:18-32.

Savill, P. S. 1983. Silviculture in windy climates. Forestry Abstracts 44:473-488.

Shugart, H. H. 1984. A theory of forest dynamics. SpringerVerlag, New York, New York, USA.

Smith, D. E. 1985. Principles of silviculture. Eighth edition John Wiley \& Sons, New York, New York, USA.

Smith, T. M., and D. L. Urban. 1988. Scale and resolution of forest structural pattern. Vegetatio 74:143-150.

Spies, T. A., J. F. Franklin, and T. B. Thomas. 1988. Coarse woody debris in Douglas-fir forests of western Oregon and Washington. Ecology 69:1689-1702.

Spies, T. A., W. J. Ripple, and G. A. Bradshaw. 1994. Dynamics and pattern of a managed coniferous forest landscape. Ecological Applications, in press.

Steele, J. H., editor. 1978. Spatial pattern in plankton communities. Plenum, New York, New York, USA.

Swanson, F. J., and J. F. Franklin. 1992. New forestry principles from ecosystem analysis of Pacific Northwest forests. Ecological Applications 2:262-274.

Thomas, J. W., E. D. Forsman, J. B. Lint, E. C. Meslow, B. R. Noon, and J. Verner. 1990. A conservation strategy for the northern spotted owl. US Forest Service and US National Park Service, Portland, Oregon, USA.

Turner, M. G. 1989. Landscape ecology: the effect of pattern on process. Annual Reviews of Ecology and Systematics 20:171-197.

US Forest Service. 1990. Land and resource management plan: Willamette National Forest. US Forest Service Pacific Northwest Region, Portland, Oregon, USA.

Watt, A. S. 1947. Pattern and process in the plant community. Journal of Ecology 35:1-22.

White, P. S. 1979. Pattern, process and natural disturbance in vegetation. Botanical Review 45:229-299.

Wilcove, D. S. 1985 . Nest predation in forest tracts and the decline of migratory songbirds. Ecology 66:1211-1214.

Wilcove, D. S., C. H. McClellan, and A. P. Dobson. 1986. Habitat fragmentation in the temperate zone. Pages 233256 in M. E. Soulé, editor. Conservation biology: the science of scarcity and diversity. Sinauer Associates, Sunderland, Massachusetts, USA. 